\title{
Kinematics of waterfall climbing in Hawaiian freshwater fishes (Gobiidae): vertical propulsion at the aquatic-terrestrial interface
}

\author{
Heiko L. Schoenfuss ${ }^{1 *}$ and Richard W. Blob ${ }^{2}$ \\ ${ }^{1}$ Department of Biological Sciences, St Cloud State University, 273 Math and Science Center, 720 Fourth Avenue South, St Cloud, MN 56301, U.S.A. \\ 2 Department of Biological Sciences, Clemson University, 132 Long Hall, Clemson, SC 29634, U.S.A. \\ (Accepted 8 April 2003)
}

\begin{abstract}
To reach adult habitats, juveniles of three species of Hawaiian gobies (fishes under $3 \mathrm{~cm}$ long) climb waterfalls up to $350 \mathrm{~m}$ high, over 10000 times their body length. The demands of moving through such an extreme environment could constrain the range of viable locomotor mechanisms that these fishes use. Previous qualitative observations indicated that Lentipes concolor and Awaous guamensis use 'powerbursts' of axial undulation to climb, whereas Sicyopterus stimpsoni 'inches up' vertical surfaces by alternately attaching oral and pelvic suckers to the substrate. To compare these propulsive mechanisms and their physiological requirements, high-speed video footage of climbing by juveniles from these three species on an artificial waterfall were collected, and climbing kinematics and performance for the two climbing styles were quantified. Bouts of powerburst climbing by L. concolor and A. guamensis typically begin in or near direct water flow and are initiated by a single, rapid adduction of the pectoral fins. Powerburst climbing bouts are rapid $\left(12.4 \pm 1.0\right.$ body lengths $\left.(B L) \mathrm{s}^{-1}\right)$, but short in duration $(0.07 \pm 0.02 \mathrm{~s})$ with few continuous locomotor cycles $\left(3.8 \pm 1.3\right.$ cycles bout $\left.{ }^{-1}\right)$. Powerburst climbers use high amplitude undulations along the entire body, but minimum resultant velocities of these undulations are high $\left(>6 \mathrm{BL} \mathrm{s}{ }^{-1}\right)$. This suggests that these species may hybridize terrestrial propulsive mechanisms with aquatic mechanisms. In contrast, climbing by inching in $S$. stimpsoni involves little axial undulation or fin movement. Sicyopterus stimpsoni typically exit the water outside of direct flow and seem to use terrestrial propulsive mechanisms. As the oral disc attaches to the substrate, it expands to almost twice its resting area, after which the posterior body is pulled upwards; once the pelvic disc attaches, the oral disc releases and the anterior body advances. Climbing bouts include several continuous cycles of disc attachment $\left(11.0 \pm 1.4\right.$ cycles bout $\left.^{-1}\right)$ and last several seconds at velocities of $0.21 \pm 0.01 \mathrm{BL} \mathrm{s}^{-1}$. Before climbing waterfalls during migration to adult habitats, $S$. stimpsoni undergo a nonfeeding metamorphosis that leads to the development of the mouth as a secondary locomotor organ. The unusual behaviour and ontogenetic strategy of $S$. stimpsoni seem to be evolutionary novelties, rather than ancestral retentions, suggesting that the evolution of these features may have been closely correlated. The substantial performance and kinematic distinctions between powerburst and inching climbing indicate that considerable locomotor diversity can evolve even in the context of extreme environmental demands.
\end{abstract}

Key words: locomotion, kinematics, performance, climbing, fishes, Gobiidae

\section{INTRODUCTION}

Animals that inhabit or traverse extreme environments often perform extraordinary behaviours in the face of severe physiological demands. The variety of ways in which animals meet these demands can reveal how physiological performance might be limited, and can suggest the extent to which the evolution of behavioural or morphological diversity in a lineage was constrained by functional requirements. For example, the freshwater ecosystem of the island of Hawai'i presents formidable obstacles that its

*All correspondence to: Heiko L. Schoenfuss.

E-mail: hschoenfuss@stcloudstate.edu fauna must overcome in order to survive and reproduce. Although fairly free from large aquatic predators, Hawaiian freshwater pools and streams are subject to frequent catastrophic disturbances including volcanic activity and hurricanes, as well as flash floods capable of sweeping freshwater animals out to sea (Fitzsimons \& Nishimoto, 1995). All species of native Hawaiian freshwater fishes (four gobies and one eleotrid; Fitzsimons, Nishimoto \& Yuen, 1993) share an amphidromous lifestyle that facilitates repopulation of upstream habitats after these frequent catastrophic disturbances, reducing the risk of local extinctions. After hatching upstream, larvae are swept downstream by currents into the ocean, where they develop for several months before returning to adult 

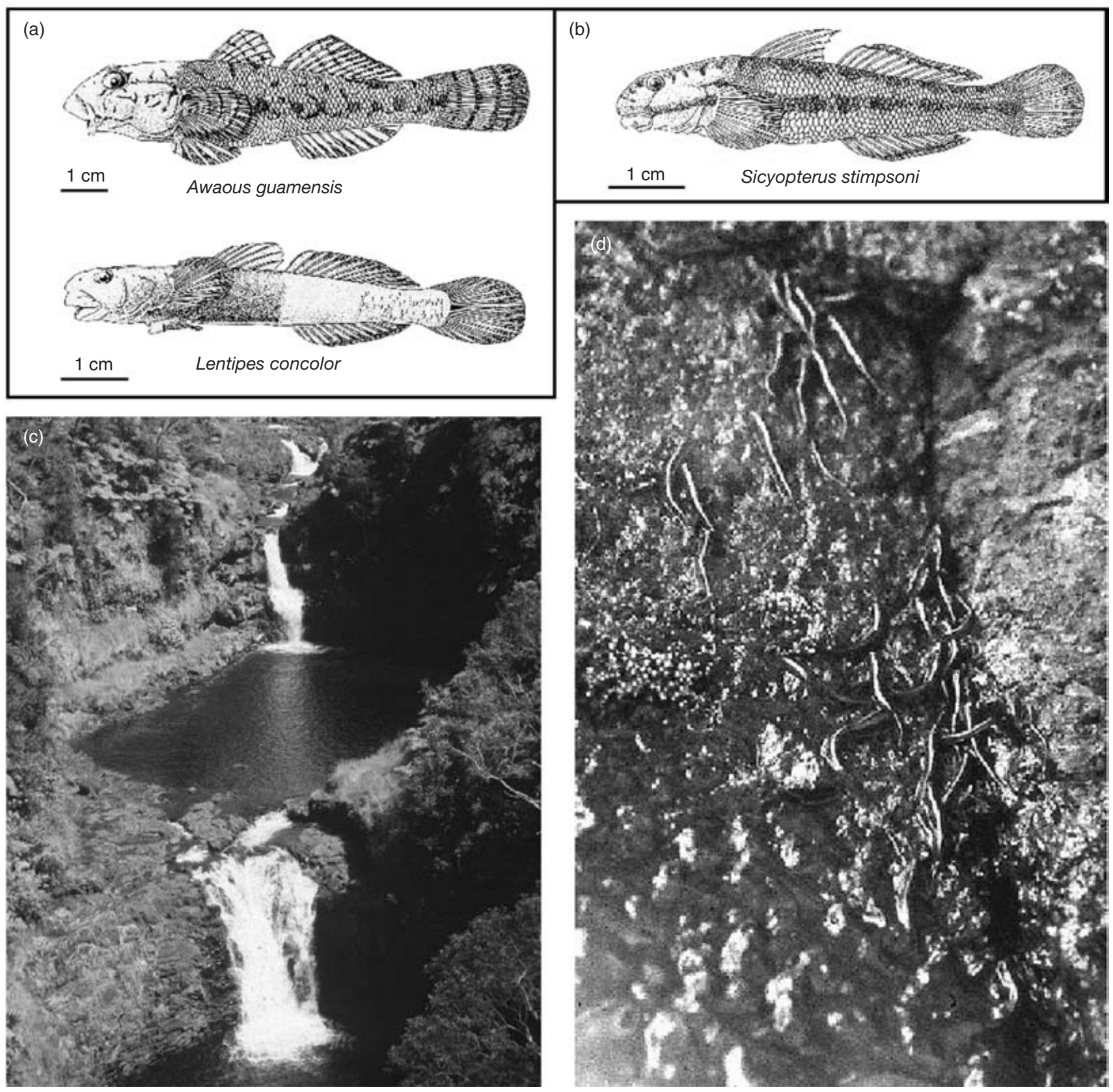

Fig. 1. Three Hawaiian climbing gobies (modified from Kinzie, 1990), and their waterfall habitats. (a) Lateral views of adults from powerburst climbing species, Awaous guamensis and Lentipes concolor. (b) Lateral view of an adult of the inching climber, Sicyopterus stimpsoni. (c) Waterfalls of Honoli'i stream on the Hamakua coast of the Island of Hawai'i ('Big Island'). (d) Climbing juvenile Sicyopterus stimpsoni on a vertical waterfall in Hakalau Stream, Island of Hawai’i. Photographs provided by D. G. K. Kuamo’o.

freshwater habitats. However, the adult habitats for three species of Hawaiian gobies (Awaous guamensis, Lentipes concolor, and Sicyopterus stimpsoni) are located upstream of substantial waterfalls, some with massive vertical drops as great as $350 \mathrm{~m}$ (Fig. 1). Because juveniles of these fish range only between 10 and $25 \mathrm{~mm}$ in length, the continued survival of these species depends upon juvenile fish successfully propelling themselves vertically, into rushing water, up a height as much as 35000 times the length of their bodies. This remarkable feat of locomotion represents a crucial episode in the life history of these animals that places stringent demands on their locomotor systems. How do these animals achieve this feat? How diverse are the locomotor mechanisms and designs that have evolved to meet the demands of this lifestyle?

Two different styles of vertical climbing have been noted in qualitative observations of juvenile Hawaiian gobies (Nishimoto \& Kuamo'o, 1992). Awaous guamensis and L. concolor have been characterized as 'powerburst' climbers (Schoenfuss, Blanchard \& Kuamo'o, 1997; Nishimoto \& Fitzsimons, 1999) that use short bursts of axial undulation interspersed with periods of attachment to the substrate by a pelvic sucking disc. This disc is formed by fusion of the pelvic fins, a feature common 

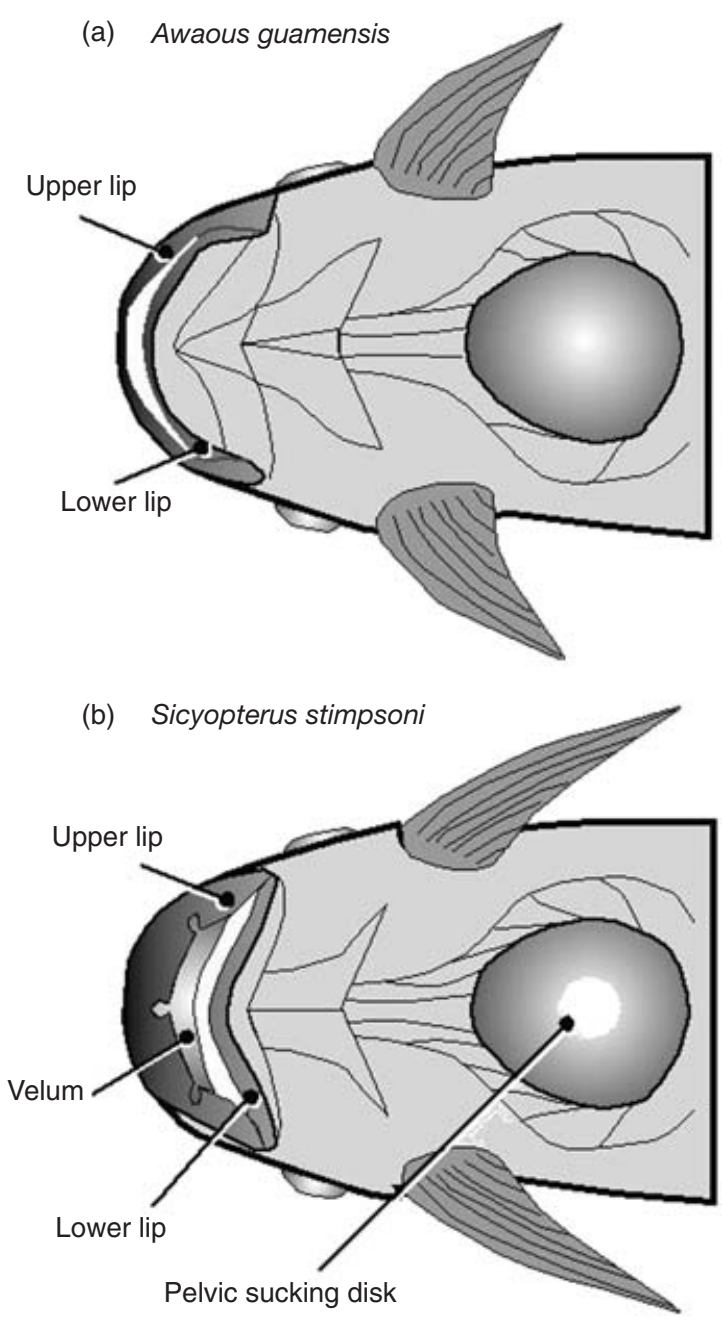

Fig. 2. Anatomical structures used in: (a) a powerburst climbing goby; (b) an inching climber.

among gobies (Fig. 2a). In contrast, S. stimpsoni has been described as 'inching' up waterfalls by alternately attaching the pelvic disc and a second, oral sucking disc (Fig. 2b) to the vertical substrate (Schoenfuss et al., 1997; Nishimoto \& Fitzsimons, 1999). Among Hawaiian freshwater fishes, the oral sucking disc is unique to S. stimpsoni and is the product of an ontogenetic strategy that differs from that of powerburst climbers. Whereas larval powerburst climbers develop for only 3 months in the ocean before upstream migration, larval $S$. stimpsoni develop for up to 6 months in the ocean and then undergo a rapid (48 h) metamorphosis that results in extensive cranial restructuring, including enlargement of the upper lip and a shift in mouth position, from terminal to ventral (Ego, 1956; Schoenfuss, 1997). Sicyopterus stimpsoni do not feed during metamorphosis, resulting in a loss of $15 \%$ body weight immediately before they commence waterfall climbing (Schoenfuss, 1997).

Although qualitative observations suggest that gobies might use different propulsive mechanisms in each style of climbing, the kinematics of 'powerburst' and 'inching' climbing have yet to be quantified. As a result, the actual range of propulsive mechanisms that these species use to climb waterfalls is uncertain, limiting our ability to evaluate the possible constraints that the demands of waterfall climbing may have placed on the functional evolution of these taxa. For example, one report briefly noted that L. concolor 'row[s] its [pectoral fins] vigorously while detaching the sucking disc' (Nishimoto \& Fitzsimons, 1999). However, all three species possess large pectoral fins that could be used to generate thrust during climbing cycles. Moreover, other diverse gobioid fishes use their fins to propel themselves over horizontal surfaces on land (Harris, 1960; Todd, 1976). Is use of the fins required for gobies to generate sufficient thrust to scale waterfalls? The relative contributions of pectoral fin and body axis movements to both styles of climbing will remain uncertain until the ranges and timing of fin and body movements have been measured in these fishes. However, with such data, it should be possible to establish whether these climbing styles represent discrete behaviours or points on a continuum.

The relationship between climbing style and climbing performance also remains to be evaluated. Observations that powerburst species rapidly move the body axis during climbing suggest that their climbing velocities will be faster than those of $S$. stimpsoni inching up surfaces, but the magnitude of this velocity difference is unknown. A large difference between the climbing styles in velocity (or duration) of locomotor bouts would carry substantial physiological implications, as it would indicate that either of two modes of locomotion, a slow endurance mode or a fast sprinting mode, could be successful in scaling vast vertical distances - in other words, both tortoise and hare strategies could finish the race. Because the requirements of endurance and sprint performance can differ markedly and are typically used to achieve different tasks (Webb, 1984; Reidy, Kerr \& Nelson, 2000), the possibility that both slow and fast modes of locomotion could be used to scale waterfalls would be noteworthy. Moreover, many fish power slow locomotion by activating only the longitudinal bands of red muscle situated laterally along the horizontal septum, recruiting white muscle only for more rapid movements (Johnston, Davison \& Goldspink, 1977; Jayne \& Lauder, 1994; Gillis, 1998b). Thus, large differences in performance between inching and powerburst climbers also could indicate that the primary muscle groups that power these modes of locomotion differ. Performance data from these two climbing styles are needed to define a functional context that could inform such hypotheses about the diversity and conservation of neuromuscular control during waterfall climbing behaviours.

An additional and, perhaps, broader issue regarding the diversity of locomotor mechanisms that these small fish can use to scale immense waterfalls, is whether climbing involves fundamentally aquatic or terrestrial propulsive mechanics. Waterfalls constitute an environment at the interface of aquatic and terrestrial habitats, but whether exclusively aquatic or terrestrial propulsive mechanisms can be used to scale them is unknown. With quantitative kinematic data from these fishes, it will be possible to test whether the two different climbing styles could, effectively, be operating in fundamentally different mechanical 
regimes, or whether either style represents a hybrid form of locomotion.

The ability to climb vertical substrates is of tremendous importance to several species of fishes from a variety of lineages in addition to the freshwater fishes of Hawai' $i$, allowing them to penetrate or repopulate habitats that otherwise might be impossible to access, e.g. catfish (Eigenmann, 1905, 1918; Evermann \& Kendall, 1905; Johnson, 1912; Kottelat, 1988; Buckup et al., 2000), eels (Moriarty, 1978), and gobies (Fukui, 1979; Ford \& Kinzie, 1982; Fitzsimons \& Nishimoto, 1996; Voegtlè, Larinier \& Bosc, 2002). However, quantified measurements of climbing kinematics and performance for fishes are lacking. This lack of data hinders the understanding of the mechanics underlying this behaviour, and hampers evaluations of diversity and potential evolutionary convergences and constraints among the locomotor behaviours of fishes. In this study, the vertical climbing kinematics and performance of juvenile Hawaiian freshwater gobies were quantified to evaluate whether the stark demands of locomotion in the extreme environment of waterfalls can constrain the range of viable locomotor mechanisms that animals use. Our analysis focuses on three specific questions about the mechanics of the highly distinctive modes of locomotion used by these animals: (1) How do the body axis and fins contribute to propulsion in each style of waterfall climbing? (2) How great is the difference in climbing performance between the two climbing styles? (3) Are waterfall climbing behaviours in gobies performed using fundamentally aquatic or terrestrial locomotor mechanisms? In the context of these questions, the implications of the differences in kinematics and performance between the climbing styles for patterns of muscle use in these species are also examined. Finally, how such differences may relate to the two ontogenetic strategies exploited by Hawaiian freshwater fishes are explored.

\section{MATERIALS AND METHODS}

\section{Animal collection, transport and maintenance}

All goby specimens were collected at the mouth of Hakalau stream, located on the Hamakua coast of the island of Hawai'i ('Big Island'), by using a passive trap designed by D. Kuamo'o (Hilo, Hawai'i, U.S.A.). Passive traps have been used extensively in previous studies (Nishimoto \& Kuamo'o, 1997) and consist of 2 wings with a stationary central collection chamber. Current is directed through the collecting chamber of the trap, where it attracts the positively rheotactic migratory juveniles of all 5 species of Hawaiian freshwater fishes, which are guided into the central chamber by the lateral wings of the trap. Trapped juveniles were removed hourly, sorted, and maintained in aerated water at ambient stream temperature $\left(10-11^{\circ} \mathrm{C}\right)$. Study animals were collected on 21 February 2000 , during a migration of juveniles following a flash flood in Hakalau stream.
Once field collections were completed, juvenile gobies were immediately shipped to facilities at the University of Minnesota (St Paul, Minnesota, U.S.A.), where the fishes were allowed to acclimate for 15 days. Throughout the acclimation period, fishes were maintained at $10-11^{\circ} \mathrm{C}$ and fed algal flake food ad libitum (Tetra, Germany). The fishes then were transported to the Field Museum of Natural History (Chicago, Illinois, U.S.A.) where locomotor trials were filmed. At the museum, fishes were allowed to acclimate for an additional $12 \mathrm{~h}$ before filming. The fishes adjusted well after both transports and throughout the 3-week period between capture and conclusion of the experiments. Fishes were observed feeding during the acclimation period and survival was high $(75 \%)$.

\section{Experimental set-up and data collection}

To provide a starting point for comparisons of the mechanisms that gobies use in both styles of waterfall climbing, baseline kinematic data were obtained from climbing Hawaiian goby species under controlled conditions that reflected (to the extent possible) the conditions that these species encounter in nature, but still allowed us to measure their behaviour and performance. An artificial waterfall was constructed (by D. Kuamo'o) so that climbing by juvenile gobies could be filmed in the laboratory (Fig. 3), providing an arena analogous to the flow tanks that are commonly used in studies of horizontal swimming. The apparatus consisted of a clear, vertical, Plexiglas climbing surface, a specimen holding pool below the climbing surface $\left(75 \mathrm{~cm}^{3}\right.$ volume), and a water delivery system mounted above the climbing surface. The use of a transparent climbing surface was essential in order for us to observe the kinematics of the sucking discs on the ventral side of each fish (a crucial component of their unusual locomotor systems). Although gobies do not typically encounter Plexiglas in the wild, water-worn rocks can be highly smoothed, and these species are frequently observed climbing very smooth rock and concrete obstacles in their stream habitats (M. Fitzsimons, pers. comm.).

The climbing surface was $20 \mathrm{~cm}$ wide and inclined $5^{\circ}$ to the vertical, matching the surface orientation juvenile gobies encounter in many waterfalls in the wild. Water flow was created by recirculating water from a holding tank with an aquarium pump, and releasing the water onto the Plexiglas climbing surface $12 \mathrm{~cm}$ above the surface of the specimen pool. Flow rate was maintained at $450 \mathrm{ml}$ $\min ^{-1}$, within the range of values these fish encounter in nature (H. Schoenfuss, pers. obs.). Small trickles of water, 2-4 $\mathrm{mm}$ in thickness (less than the dorsoventral height of each fish), were created by dividing the water sheet with straws attached to the climbing surface just below the water outflow. Because the water trickles varied slightly in breadth and meandered to different degrees across the waterfall surface, flow velocity differed among trickles. As the fish climbed up the clear vertical Plexiglas, locomotor trials were filmed in ventral view with a 


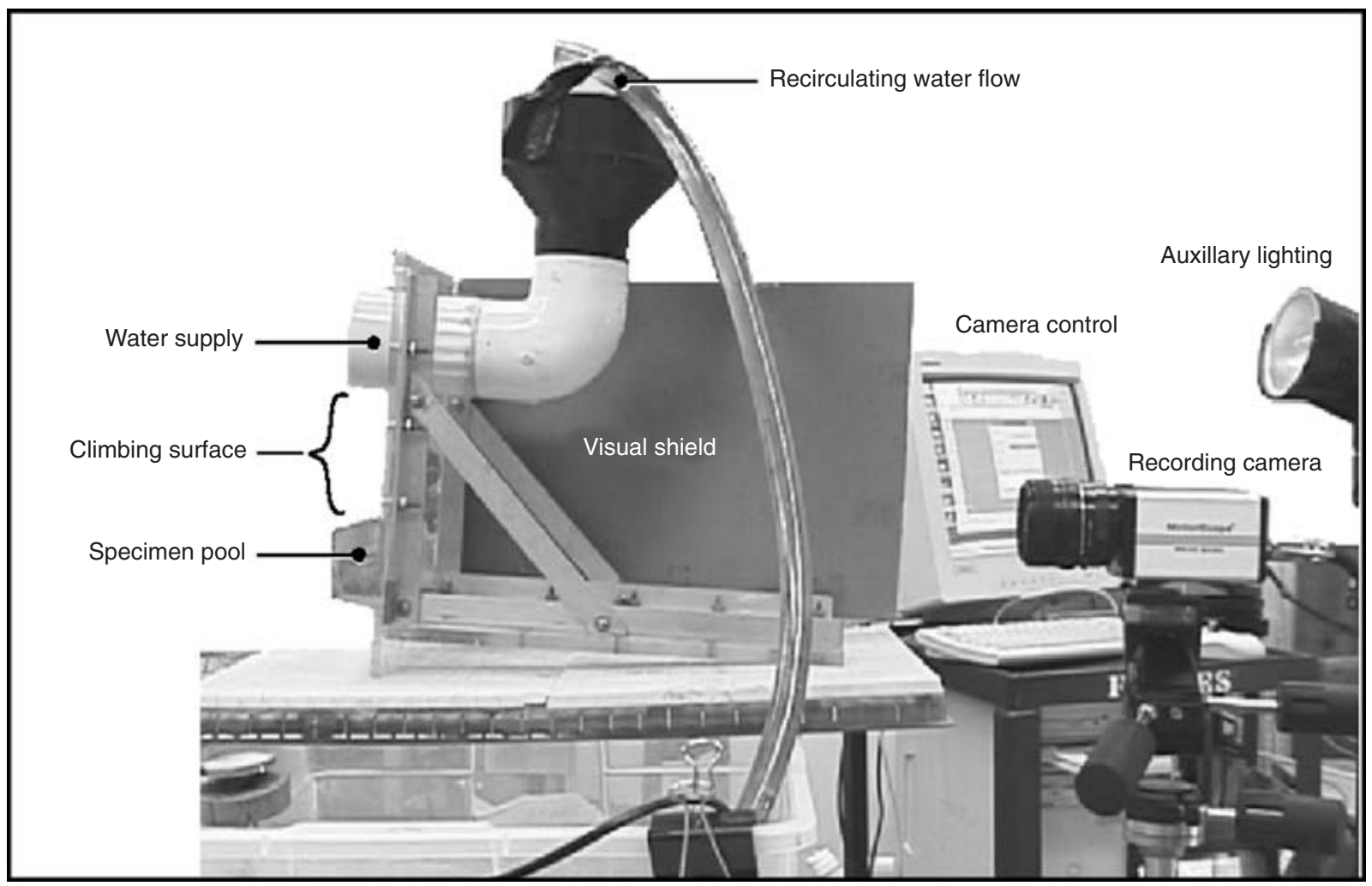

Fig. 3. Artificial waterfall and recording set-up used in this study. Visual shields on front and sides of artificial waterfall removed for the purpose of this picture, but were in place for all recordings to prevent interference with behaviour of fishes being recorded.

high-speed digital video camera (Redlake MotionScope PCI 1000S; Fig. 3). Trials for S. stimpsoni were filmed at either $125 \mathrm{~Hz}$ or $250 \mathrm{~Hz}$, but all trials by A. guamensis and L. concolor were filmed at $250 \mathrm{~Hz}$.

In addition to being strongly attracted to current (positive rheotaxis), all species of Hawaiian freshwater gobies also seem to be stimulated to climb by the odour of conspecifics (P. Sorensen, pers. comm.). Therefore, to initiate climbing trials, groups of 3-5 animals were placed together in the specimen pool. Because S. stimpsoni can be easily distinguished from other species by the presence of the oral sucking disc, it was possible to group juveniles exclusively from this species in the specimen holding pool for locomotor trials. In contrast, distinguishing the postlarval juveniles of A. guamensis and L. concolor from each other requires close examination of specimens under magnification, subjecting them to severe stress. To avoid this stress before performance trials, identifications of specimens as $A$. guamensis or $L$. concolor were made after all recordings of locomotion were completed. As a result, specimens from these species were placed together in the holding pool and it was impossible to determine which of these 2 species performed a particular climbing bout. Therefore, it was necessary to pool locomotor data from A. guamensis and L. concolor. However, these 2 species use the same general style of powerburst climbing in the wild (Nishimoto \& Kuamo'o, 1992, 1997; Tate, 1997), and kinematic data did not indicate clearly bimodal patterns that would suggest species-specific variations in the kinematics of powerburst climbing (see Results). Thus, pooled locomotor data from A. guamensis and L. concolor seem to be adequate to allow kinematic differences to be quantified between powerburst climbing by $A$. guamensis and $L$. concolor and climbing by alternating oral and pelvic substrate attachment as seen in S. stimpsoni.

Post-trial identifications indicated that $11 \mathrm{~S}$. stimpsoni (total length (TL) 20-24 mm, body mass (BM) 0.106$0.195 \mathrm{~g}$ ), 12 A. guamensis (14-16 mm TL, 0.065-0.073 g $\mathrm{BM})$, and $9 \mathrm{~L}$. concolor $(12-14 \mathrm{~mm} \mathrm{TL}, 0.063-0.070 \mathrm{~g}$ $\mathrm{BM})$ were used in locomotor trials. To avoid excessive stress on the fishes, no attempt was made to mark individual animals. However, variations in body size and pigmentation patterns of the animals filmed indicated that several different members of each species contributed to the data that were analysed for each climbing behaviour. In addition, after a series of climbing bouts was filmed, groups of fish were moved into a separate tank and replaced with previously untested individuals, thus ensuring that all fish were given the opportunity to climb.

\section{Data analysis}

Data were extracted from the video footage for comparisons of 3 types of variables between powerburst climbing and climbing by alternating oral and pelvic substrate attachment: (1) exit location from the water pool; (2) climbing kinematics; (3) velocity and duration of individual climbing cycles and complete bouts of consecutive 
climbing cycles. Only trials in which the fish climbed upwards $\left(<25^{\circ}\right.$ from vertical $)$ were analysed.

\section{Exit location from the water pool}

To facilitate evaluations of whether each climbing style was fundamentally aquatic or terrestrial, the location that fish exited the holding pool with respect to the water stream was recorded for the onset of each climbing sequence. An exit event was counted each time an animal broke the plane of the water in the specimen pool and initiated at least 1 full climbing cycle. Three broad categories of exit events were recognized: (1) water: $>$ one-half the width of the fish was immersed in the stream current as it emerged from the pool; (2) periphery: while emerging from the pool, the fish was offset by $<1$ body width from the edge of the water stream, or was immersed in it by $<$ one-half body width; (3) outside flow: the fish exited the pool at a location $>1$ body width from the edge of a water stream. In addition, because the fishes diverged slightly from a strictly vertical travel direction in almost all exit events, peripheral exit locations were further subdivided as either being directed towards the water stream or away from water flow. To evaluate whether powerburst climbers or inching climbers preferred particular exit locations, the distribution of observed pool exit locations for each of these groups was compared to expectations for a random distribution of locations (i.e. no preferences) with singleclass classification tests for goodness of fit (Sokal \& Rohlf, 1995).

\section{Climbing kinematics}

To quantify climbing kinematics, digital video sequences of goby locomotion were saved as Quicktime files, and the positions of landmarks on the bodies of the fishes were digitized using a modification of the public domain NIH Image program for Apple Macintosh, developed at the U.S. National Institutes of Health and available on the internet at http://rsb.info.nih.gov//nih-image/ (the modification, QuickImage, was developed by J. Walker and is available at http://www.usm.maine.edu/ walker/ software.html). For powerburst climbing by A. guamensis and $L$. concolor, movements of the pectoral fins and body axis were measured separately. To quantify fin movement, the base and tip of the left and right pectoral fins were digitized for each frame of sequences of fin motion, along with 2 points along the midline of the head to serve as a reference for the instantaneous direction of travel. From these coordinates, the angle of each fin relative to the direction of travel was calculated for each frame, allowing calculation of angular velocities of the fins and evaluation of the synchronicity of left and right fin movements. These data allowed us to evaluate when the fins moved and, therefore, when they might contribute to thrust generation during each climbing cycle.

Axial locomotor cycles were defined as all the events between sequential achievement of maximum amplitude at the middle of 1 side of the body. To calculate the axial kinematics of powerburst climbers, 15 points were digitized along the midline of the fish for every frame of a locomotor cycle, with the first point marking the anteriormost extent of the head and the last point marking the tip of the tail. Identification of the midline was facilitated by the presence of a dark line of pigmentation running anterior to posterior along the body of the larva. For each frame, 101 equally spaced points were interpolated from the 15 digitized points with the software QuicKurve (Walker, 2000; program available at http://www. usm.maine.edu/ walker/software.html). From these interpolated points, the coordinates were extracted of 11 evenly spaced points along the length of the body to divide the body into 10 segments, each of which was $10 \%$ of body length. To aid evaluations of axial mechanics during powerburst locomotion, custom software was developed in Matlab (Mathworks) to calculate the following parameters for every frame of each locomotor cycle analysed from the coordinates of the 11 equally spaced midline points and the orientations of the 10 equal body segments: (1) the angle of each body segment to the direction of travel; (2) the amplitude of each landmark point relative to a straight body midline; (3) the instantaneous resultant velocity of each landmark point (parameter definitions follow those of Gillis, 1998a). Measurements of segment angles and undulatory amplitudes along the body were performed to help identify which parts of the fish contribute to thrust generation. For example, during undulation on terrestrial substrates, points along the body where low minimum resultant velocities and low undulatory amplitudes coincide are believed to indicate the primary regions where propulsive forces are generated against the substrate (Gillis, 1998a).

The climbing kinematics of S. stimpsoni differed substantially from those of the powerburst climbers and required the use of a different analytical protocol. Climbing cycles in S. stimpsoni were defined as the events occurring between sequential upward movements of the pelvic sucking disc. For each frame of a locomotor cycle, we digitized the positions of 10 anatomical landmarks: the anterior edge of the upper lip at the midline, the posterior edge of the lower lip at the midline, the left and right edges of the mouth, the bases and tips of the left and right pectoral fins, the anterior edge of the pelvic sucking disc at the midline, and the midline anal opening. From these coordinates, a custom Matlab routine was used to calculate the instantaneous position of the anterior edges of the mouth and the pelvic sucking disc. An index of the instantaneous surface area enclosed by the oral sucking disc was also calculated:

$$
\text { mouth area }=(\pi / 4)\left(D_{\mathrm{LR}}\right)\left(\mathrm{D}_{\mathrm{AP}}\right)
$$

where $D_{L R}$ and $D_{A P}$ are the instantaneous distances between the left and right edges of the mouth and the anterior and posterior edges of the mouth, respectively. Although this index simplifies the shape of the mouth and, therefore, does not measure the actual area of the oral disc, it allows us to evaluate changes in anteroposterior and lateral mouth dimensions that effectively track whether the oral disc is increasing or decreasing in 
Table 1. Water pool exit locations at the onset of climbing for goby species using powerburst climbing $v s$ climbing by inching

\begin{tabular}{|c|c|c|c|c|c|}
\hline \multirow[b]{3}{*}{ Species } & \multirow[b]{3}{*}{$\begin{array}{l}\text { Behaviour } \\
\text { (no. of observations) }\end{array}$} & \multicolumn{4}{|c|}{ Water pool exit location } \\
\hline & & \multicolumn{3}{|c|}{ Periphery } & \multirow[b]{2}{*}{$\begin{array}{l}\text { Outside water } \\
\text { flow (\%) }\end{array}$} \\
\hline & & Water $(\%)$ & $\begin{array}{l}\text { Toward } \\
\text { water }(\%)\end{array}$ & $\begin{array}{l}\text { Away from } \\
\text { water }(\%)\end{array}$ & \\
\hline A. guamensis/L. concolor & Powerburst $(85)^{\mathrm{a}}$ & $22(25.9)$ & $15(17.6)$ & $32(37.6)$ & $16(18.8)$ \\
\hline S. stimpsoni & Inching $(10)^{\mathrm{b}}$ & $1(10.0)$ & $0(0)$ & $4(40.0)$ & $5(50.0)$ \\
\hline
\end{tabular}

a Distribution differs significantly from random: single classification test for goodness of fit (Sokal \& Rohlf, 1995), d.f. =3, Williams corrected $G=34.629, P<0.001$ (Rohlf \& Sokal, 1995).

${ }^{\mathrm{b}}$ Distribution differs significantly from random based on single classification tests for goodness of fit: with unpooled categories and adjustment for zero observations in a class, d.f. $=3$, Williams corrected $G=7.787, P<0.025$; with water and outside flow categories pooled to provide expected frequencies $\geq 5$ per category (Sokal \& Rohlf, 1995), d.f. $=1$, Williams corrected $G=7.011, P<0.01$ (Rohlf \& Sokal, 1995).

area. After evaluating these parameters, the software QuickSAND (Walker, 1998; program available at http:// www.usm.maine.edu/ walker/software.html) was used to fit a quintic spline to the kinematic calculations for each trial, smooth the data, and normalize all the trials to the same duration in order to calculate mean kinematic profiles for each variable.

ANOVAs indicated that climbing parameters were not correlated with water exit location. Therefore, trials from all exit locations were pooled within each climbing style for statistical comparisons of kinematic and performance variables.

\section{Velocity and duration of climbing cycles and bouts}

The average velocity of each locomotor cycle was calculated as the distance travelled by the point marking the anal opening of each fish, divided by the duration of the locomotor cycle. Cycle frequencies were calculated as the inverse of cycle duration. Climbing bouts were defined as sequences of continuous locomotor cycles. The number of consecutive climbing cycles per bout was counted for a sample of locomotor trials. The durations of these climbing bouts were recorded, as were the total distances travelled. Comparisons of velocity and duration parameters between powerburst climbing and climbing by alternate oral and pelvic attachment were performed with non-parametric Mann-Whitney $U$-tests.

\section{RESULTS}

\section{Holding pool exit locations relative to water flow}

Hawaiian gobies that use powerburst climbing (A. guamensis and L. concolor) usually initiated climbing bouts by breaking the water plane at the periphery of the flowing current of water (47 of 85 observations) (Table 1). In two-thirds of these peripheral ascents (32 of 47 observations) the animal initially travelled away from the stream of water before climbing vertically, whereas the remaining 15 peripheral ascents initially were directed towards the water stream. Twenty-two ascents $(25.8 \%)$ began in the water stream and 16 ascents $(18.8 \%)$ began outside the stream of flowing water. This distribution of exit locations deviates significantly from the even distribution of exit locations that would be expected if powerburst climbers exhibited no preference for particular exit locations (Table 1).

The distribution of exit locations for S. stimpsoni also deviates significantly from the even distribution of exit locations that would be expected if this species exhibited no preference for particular exit locations (Table 1). However, in contrast to the powerburst climbers, S. stimpsoni most frequently emerged from the specimen pool outside of the water flow (five of 10 observations). Though four of 10 ascents by S. stimpsoni began at the periphery of the water stream, all four of these initially angled away from the flowing water. Sicyopterus stimpsoni emerged directly into the water current in only one observation.

\section{Climbing kinematics of $\boldsymbol{A}$. guamensis and $\boldsymbol{L}$. concolor: pectoral fin adduction and axial powerbursts}

Climbing bouts by A. guamensis and L. concolor were driven by powerful undulations of the body axis, but typically were initiated by rapid adduction of the pectoral fins. At rest before climbing, with the pelvic sucking disc attached to the vertical surface, the pectoral fins were angled $121 \pm 4^{\circ}$ from the body axis (Fig. 4a). The trailing edges of the pectoral fins were directed ventrally, but bent anteriorly once they met the climbing surface, providing additional surfaces of contact with the substrate. As undulation of the body axis began, the pectoral fins were rapidly adducted, with maximum angular velocities reaching $6 \pm 1^{\circ} \mathrm{ms}^{-1}$ (Fig. 4b). Adduction of both pectoral fins occurred nearly synchronously, with a mean lag between completion of left and right side pectoral adduction of only $10 \pm 2 \%$ cycle duration. After a single pectoral adduction event (mean duration 

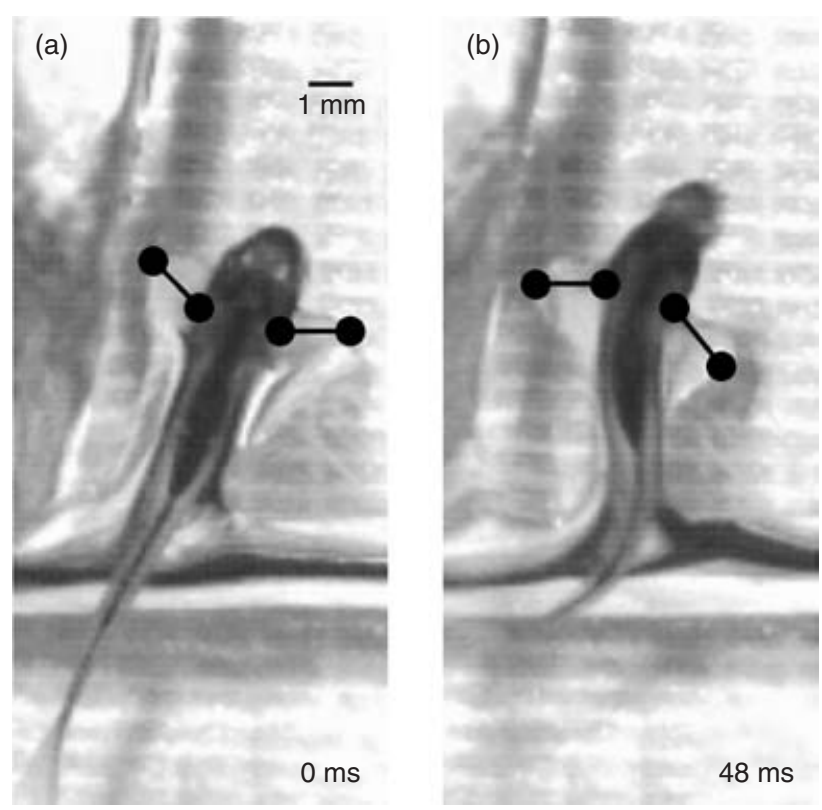

Fig. 4. Pectoral fin adduction at the initiation of a vertical powerburst climbing cycle by Awaous guamensis or Lentipes concolor. Representative frames from a single adduction event are shown. Positions of the left and right pectoral fins are marked with black dots and line segments. (a) Resting fin position at start of event. Note extensive contact of the fin with the vertical wall (b) Fin adduction at just past the midpoint of the first climbing cycle.

$51 \pm 6 \mathrm{~ms}, n=7$ ), climbing was accomplished by a series of rapid cycles of body axis undulation, during which the pectoral fins remained adducted along the sides of the body. Several bouts were recorded in which a series of significantly slower pectoral fin adduction cycles (mean cycle duration $77 \pm 5 \mathrm{~ms}, n=19$ cycles, Mann-Whitney $U$-test $P=0.004$ ) occurred sequentially, with only small, single undulations of the body axis per cycle. However, these cycles seem to be used to make minor adjustments in position, rather than as a mode of climbing extended distances, because the direction of travel was often lateral rather than vertical, bouts of sequential fin adduction were not sustained $(3.4 \pm 0.5$ cycles per bout, $n=18$ bouts), and the distance travelled per bout $(0.38 \pm 0.08 \mathrm{BL}$ (body lengths), $n=6$ ) was more than four times shorter (Mann-Whitney $U$-test $P=0.003$ ) than in bouts of axial climbing $(1.60 \pm 0.51 \mathrm{BL}, n=8)$.

The axial component of powerburst climbing was characterized by undulations of the whole body resulting in large maximum angles of all body segments relative to the direction of travel (mean maximum $=31-60^{\circ}$ per segment, $n=19$ cycles; Fig. 5). The smallest maximum segment angles occurred near the pelvic sucking disc (segments 3-5), whereas the largest angles occurred in the head and tail segments. In addition, maximum amplitudes and resultant velocities were high at all points along the length of the body (Fig. 6). Peak amplitudes ranged from c. $10 \% \mathrm{BL}$ at point 4 (located at $30 \% \mathrm{BL}$ from the head),

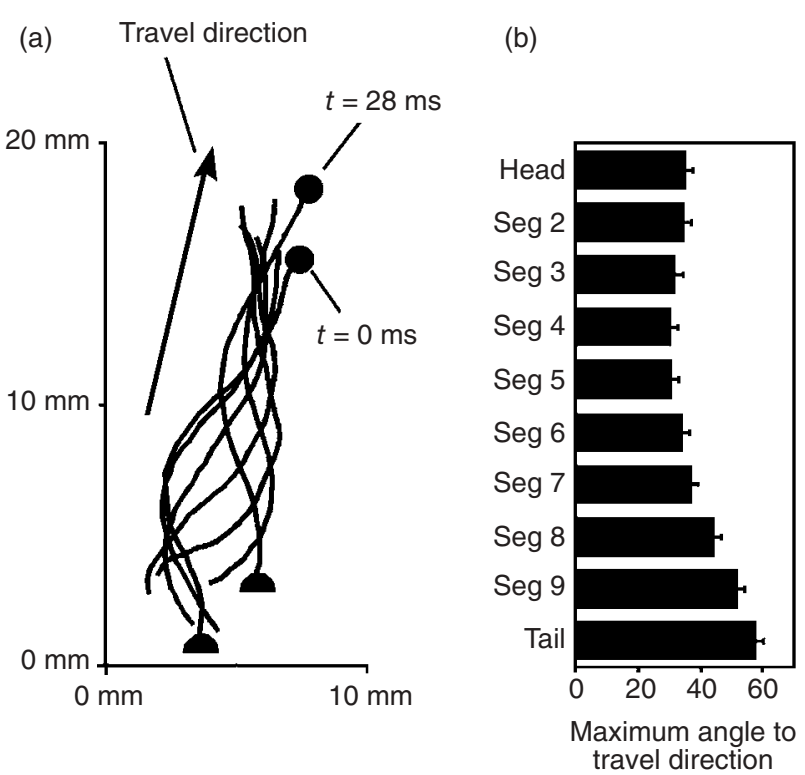

Fig. 5. Axial kinematics during vertical powerburst climbing by Awaous guamensis and Lentipes concolor. (a) Sequential tracings of the midline for powerburst climbing larvae through one complete representative tailbeat cycle. The beginning and end of the cycle (marked by the maximum left-side amplitude at midbody) are marked by the tracings with the head (filled circle) and tail (halfcircle) symbols. Direction of travel and time $(t)$ for start and end of cycle are shown. (b) Maximum angles of body segments to the direction of travel for powerburst climbers. Bars for each equallength segment plot the mean ( $\pm 1 \mathrm{SE}, n=17$ cycles) maximum angle of the segment to the direction of travel at any point during the cycle.

to much higher values $(15-20 \% \mathrm{BL})$ at the head and tail. Similar to segment angles, the lowest lateral displacements were recorded at points closest to the pelvic sucking disk, c. $30-40 \%$ posteriorly along the length of the body (points 4 and 5) (Fig. 6a). Minimum resultant velocities of points along the body were also greatest at the head and tail and lowest at intermediate locations, but were high (8-13 $\left.\mathrm{BL} \mathrm{s}^{-1}\right)$ along the entire length of the body and showed a smaller range of variation than amplitude or maximum segment angle (Fig. 6b). The duration of axial cycles during power burst locomotion is $c$. one-third of that during pectoral adduction.

\section{Climbing kinematics of $S$. stimpsoni: alternating oral and pelvic substrate attachment}

Four major events can be recognized in the climbing cycle of $S$. stimpsoni as it inches up vertical surfaces.

(1) The cycle begins with a decrease in the surface area of the mouth that reflects the detachment of the oral sucking disc from the climbing surface (Figs $7 \mathrm{a} \&$ 8a). The pelvic disc shows little movement during this time, indicating that it remains firmly attached to the substrate through this interval (Figs 7a \& 8c). 
(a)

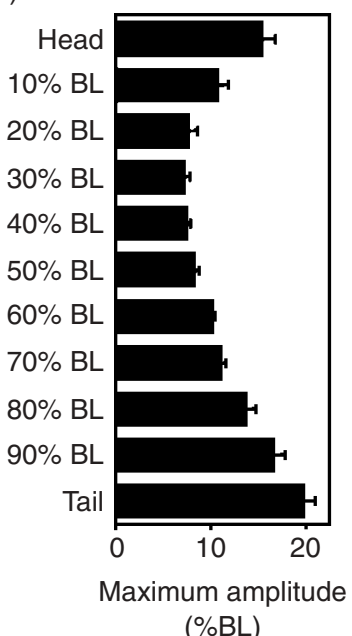

(b)

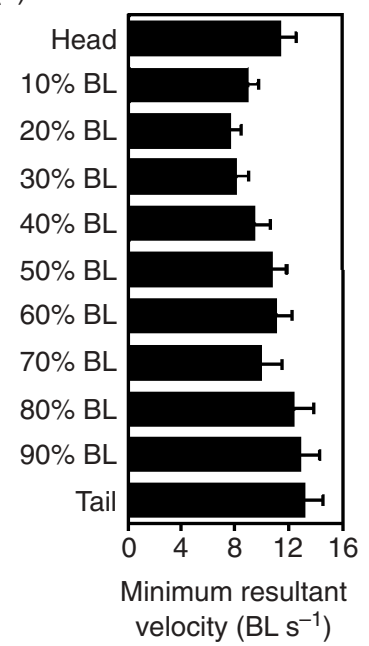

Fig. 6. Axial kinematics during vertical powerburst climbing by Awaous guamensis and Lentipes concolor. (a) Mean $( \pm 1 \mathrm{SE}$, $n=17$ cycles) maximum amplitudes throughout the climbing cycle for each of 11 equally spaced points along the length of the larvae, normalized as a percentage of body length (BL). (b) Mean ( $\pm 1 \mathrm{SE}, n=17$ cycles) minimum resultant velocities throughout the climbing cycle for the same 11 equally spaced points along the length of the larvae, in $\mathrm{BL} \mathrm{s}{ }^{-1}$. Note that the location with the lowest maximum amplitudes corresponds to the location exhibiting the lowest minimum resultant velocities, but that resultant velocities are high along the entire length of the body.

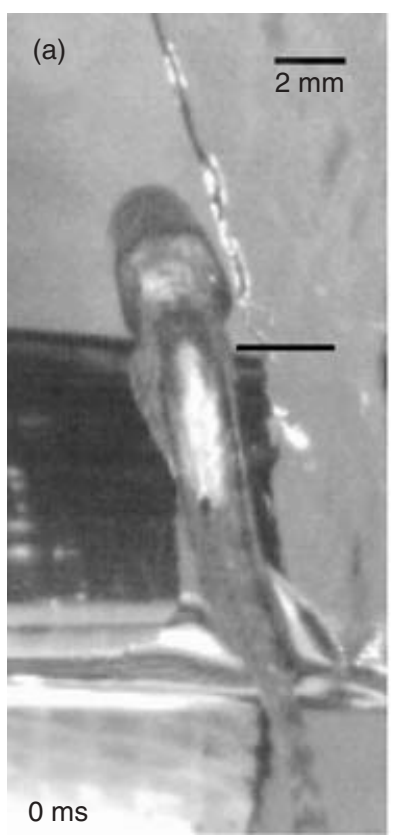

Start

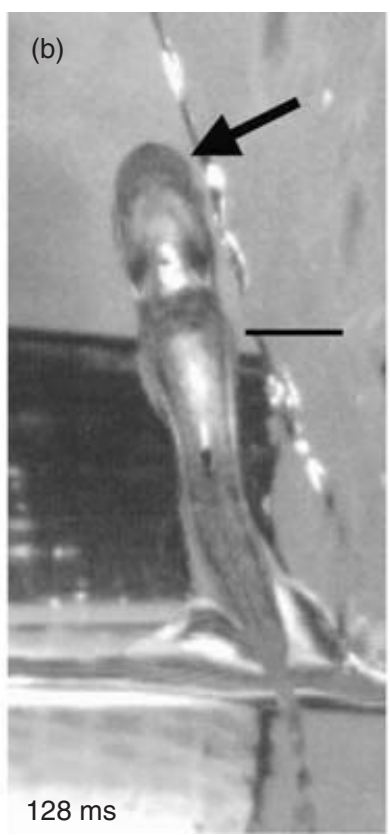

Head advances, mouth area shrinks

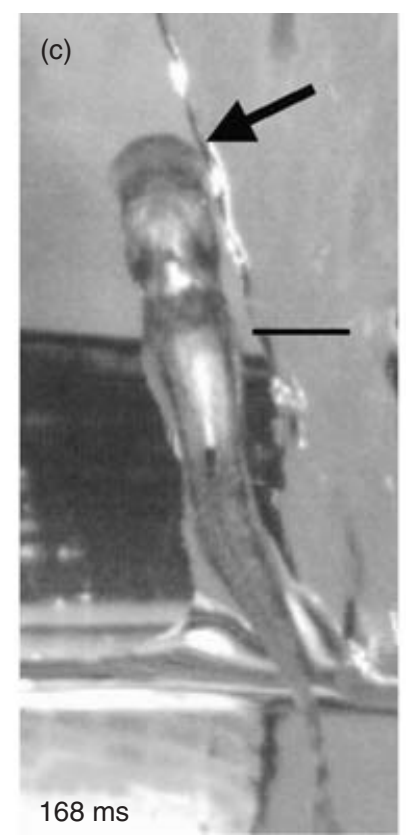

Mouth area expands

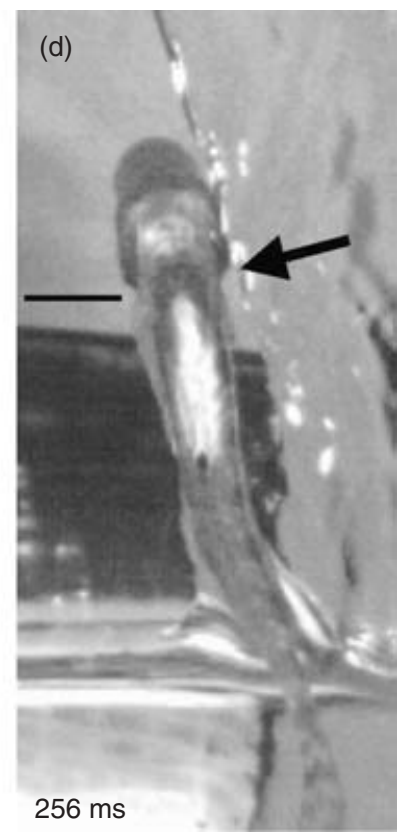

Pelvic disc advances

Fig. 7. Frames from a representative cycle of inching climbing by Sicyopterus stimpsoni. Black arrows point to regions where the kinematic events occur that are labelled under each frame. Black horizontal lines, height of the posterior margin of the pelvic sucking disc in each frame. (a) Start of the climbing cycle. (b) Initial events during the cycle include a shrinking of the mouth surface area as it detaches from the surface, and upward advancing of the head. (c) After head advancement, mouth area re-expands as the oral disc reattaches to the surface. (d) Upon reattachment of the mouth to the surface, the pelvic disc begins to advance upwards. 

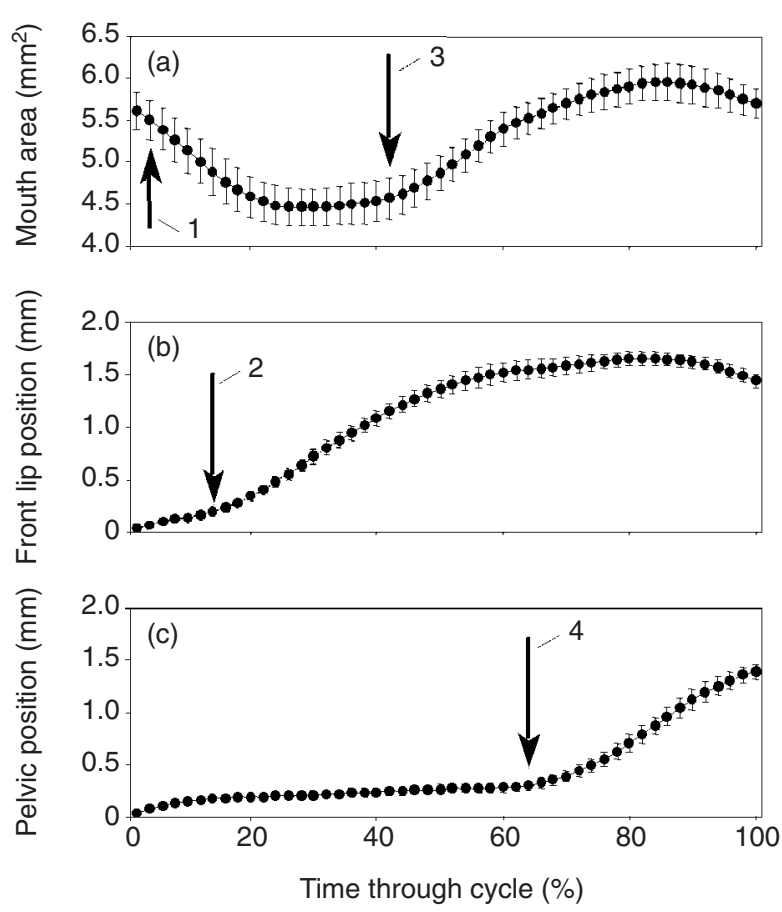

Fig. 8. Mean profiles for kinematic variables during inching climbing by Sicyopterus stimpsoni ( $n=26$ climbing cycles). Each climbing cycle was normalized to the same duration and values of kinematic variables were interpolated for 50 equally spaced increments through the stroke cycle (see Walker, 1998). Plots for each variable illustrate means $\pm 1 \mathrm{SE}$ for each $2 \%$ increment of time through the climbing cycle. (a) Instantaneous mouth area $\left(\mathrm{mm}^{2}\right.$, see text for calculation). (b) Cumulative position of the front edge of the lip (displacement since the start of the cycle, $\mathrm{mm}$ ). (c) Cumulative position of the anterior edge of the pelvic sucking disc (displacement since the start of the cycle, mm). Arrows, start of each of the four major events in the climbing cycle of $S$. stimpsoni illustrated in Fig. 7: (1) mouth area decreases as mouth detaches from the surface; (2) head advances; (3) mouth area increases as the oral sucking disc reattaches to the surface; (4) pelvic disc detaches from surface and advances.

substrate (Table 2). Forward velocities achieved during continuous axial locomotor cycles by powerburst climbing species (in $\mathrm{m} \mathrm{s}^{-1}$ ) were 38 times greater than those achieved in S. stimpsoni as it inched up vertical surfaces. When normalized for body length (12-16 $\mathrm{mm}$ for juvenile A. guamensis and L. concolor, $22 \mathrm{~mm}$ for juvenile S. stimpsoni), cycle velocity was 59 times greater during continuous axial locomotor cycles in the powerburst climbers. Similarly, cycle frequency was $>11$ times greater during powerburst climbing. The frequencies achieved by powerburst climbers $(51.2 \pm 1.5 \mathrm{~Hz})$ are comparable to those reported for other larval fishes of similar size (30-55 Hz: Hunter, 1972; Hunter \& Kimbrell, 1979; Batty, 1981). As a result of these climbing velocities and cycle frequencies, powerburst climbers advanced an average of $4.5 \mathrm{~mm}$ per cycle, whereas $S$. stimpsoni advanced an average of $1.4 \mathrm{~mm}$ per cycle. However, as S. stimpsoni inched up surfaces it was able to sustain
Table 2. Comparison of velocity and duration parameters ( \pm SE) for climbing cycles by goby species using powerburst climbing (A. guamensis and L. concolor) and inching (S. stimpsoni). Sample sizes in parentheses. $P$ values based on non-parametric MannWhitney $U$-tests. Cycle parameters for $S$. stimpsoni were calculated from a subset of the total cycles for bouts; therefore, the cycle frequency reported differs slightly from the value expected based on dividing bout duration by cycles per bout

\begin{tabular}{|c|c|c|c|}
\hline Variable & $\begin{array}{l}\text { A. guamensis/ } \\
\text { L. concolor }\end{array}$ & S. stimpsoni & $P$ \\
\hline $\begin{array}{l}\text { Velocity } \\
\qquad\left(\mathrm{m} \mathrm{s}^{-1}\right)\end{array}$ & $0.23 \pm 0.02(17)$ & $0.006 \pm 0.0003(26)$ & $<0.001$ \\
\hline $\begin{array}{l}\text { Velocity } \\
\qquad\left(\mathrm{BL} \mathrm{s} \mathrm{s}^{-1}\right)\end{array}$ & $12.4 \pm 1.0(17)$ & $0.21 \pm 0.01(26)$ & $<0.001$ \\
\hline $\begin{array}{l}\text { Cycle frequency } \\
(\mathrm{Hz})\end{array}$ & $51.2 \pm 1.5(17)$ & $4.4 \pm 0.2(26)$ & $<0.001$ \\
\hline Cycles per bout & $3.8 \pm 1.3(17)$ & $11.0 \pm 1.4(6)$ & 0.002 \\
\hline Bout duration (s) & $0.07 \pm 0.02(17)$ & $2.8 \pm 0.3(6)$ & $<0.001$ \\
\hline
\end{tabular}

three times the number of continuous climbing cycles as the powerburst climbers, producing climbing bouts that lasted 40 times longer (Table 2) and traversed nearly the same total distance $(15.4 \mathrm{~mm} v s 18.9 \mathrm{~mm})$ as powerburst climbers. Thus, brief bouts consisting of a few rapid locomotor cycles characterized powerburst climbing in A. guamensis and L. concolor, whereas longer bouts consisting of several slow locomotor cycles characterized climbing by alternating oral and pelvic suction in S. stimpsoni.

\section{DISCUSSION}

There were five critical differences between the powerburst climbing used by $A$. guamensis and $L$. concolor and the inching climbing used by $S$. stimpsoni. (1) A. guamensis and L. concolor ascended vertical surfaces primarily by climbing into or along the edge of current, whereas $S$. stimpsoni climbed preferentially on the periphery of or outside of flowing water (Fig. 7, Table 1). (2) Powerburst climbing consisted of significantly faster locomotor cycles than climbing by alternating oral and pelvic attachment. (3) Bouts of powerburst climbing consisted of fewer cycles and lasted for a shorter total duration than bouts of inching-up vertical surfaces. (4) Powerburst climbing was initiated by a distinct phase of pectoral fin adduction, which was usually absent in the locomotion of S. stimpsoni. (5) Movements of most of the body contributed to thrust in powerburst climbing, whereas only a short length of the body musculature (anterior to the pelvic disc) seemed to contribute to climbing by alternate oral and pelvic attachment to the substrate. These results provide evidence that diverse mechanisms can be used during vertical propulsion in habitats at the aquatic-terrestrial interface, and suggest differences between the physiological requirements of these climbing styles that seem to correspond to the contrasting ecological strategies used by these goby species. 


\section{Structures contributing to propulsion in powerburst and inching-up climbing}

Locomotor mechanics depend fundamentally on the body structures that are used to generate propulsion, because differences in the ways that structures move affect how they produce propulsive forces. Our results indicate that there is a nearly complete distinction between how body structures are used in the two climbing styles used by Hawaiian gobies. Powerburst climbing is initiated by a single, rapid adduction of the pectoral fins and is sustained through rapid undulations of the entire body axis. In contrast, inching uses neither fin movements nor body axis undulations, relying instead on longitudinal advancement of alternating portions of the body axis while one of two sucking discs is attached to the climbing surface. Inching is clearly not a supplement to axial undulation in S. stimpsoni, but rather seems to be the only mode of climbing that these fishes perform.

Although all species of Hawaiian gobies possess prominent pectoral fins, these seem to make limited contributions to sustained vertical locomotion during waterfall climbing. For $S$. stimpsoni, pectoral fin movements were negligible in most climbing bouts and cycles. In powerburst climbers (A. guamensis and $L$. concolor), single pectoral fin aduction events, synchronous on both sides of the body, initiate bouts of axially propelled climbing by providing initial acceleration from rest. In particular, the fact that the trailing edges of the pectoral fins make substantial contact with the substrate in powerburst gobies before climbing cycles suggests that they are used to produce a ground reaction force that helps propel the fish upwards. However, sequential cycles of pectoral fin adduction seem to be used only to make minor adjustments in position on vertical substrates, rather than to power extended sequences of climbing cycles. These patterns of fin use contrast with those reported for other gobioid fishes moving over horizontal substrates. For example, the mudskipper Periophthalmus koelreuteri performs synchronized crutching with the pectoral fins in order to move over land (Harris, 1960). The Pacific goby Gobionellus sagittula also travels overland, grazing on films of detritus and invertebrates (Todd, 1976). Sustained terrestrial locomotion in this species is also powered by synchronous retraction of the pectoral fins at slow speeds, but is powered by coordinated pectoral fin retraction and beats of the tail at fast speeds (Todd, 1976). The kinematic variation present in this small sample of species suggests the potential for considerable diversity in the locomotory role and, potentially, the neuromotor control of the pectoral fins among gobies that move over solid substrates. With kinematic data from additional taxa, it should be possible to evaluate the evolutionary history of these patterns of fin use among gobies by mapping their functional traits onto available phylogenetic hypotheses for the group (e.g. Parenti \& Thomas, 1998).

Some axial muscular and skeletal structures are used in both types of climbing used by Hawaiian freshwater gobies, but they are used in significantly different ways. Powerburst climbing involves the production of body axis undulations similar to those used by many fishes during swimming (e.g. Long, McHenry \& Boetticher, 1994; Jayne \& Lauder, 1995; Gillis, 1996) and terrestrial locomotion (Gillis, 1998a). Climbing by inching, however, requires segments of axial muscles anterior to the pelvic fins to alternately pull the posterior body of the goby up the vertical substrate of the waterfall and then advance its head. Precisely how these movements are achieved in S. stimpsoni is difficult to evaluate from our ventral-view video footage. The close attachment of the skin to the underlying musculature and, thereby, to the vertebral column in most fishes (Wainwright, Vosburgh \& Hebrank, 1978) suggests that the use of internal concertina mechanisms (similar to those used by some caecilians: Summers \& O'Reilly, 1997) is unlikely. An 'inch-worm' mechanism (with dorsoventral flexion) seems a more viable possibility, but it is unclear how this would be controlled. Electromyographic measurements in combination with lateral views of climbing kinematics could be used to resolve this question. However, performance data suggest that the longitudinal red muscle bundles could play an important role in the climbing of S. stimpsoni (see below).

\section{Physiological implications of performance differences between inching and powerburst climbing}

Powerburst climbing is characterized by considerably more rapid locomotor cycles than inching. For comparison, if both climbing styles were used continuously to scale a $100 \mathrm{~m}$ waterfall, the powerburst climber would reach the top in $7.25 \mathrm{~min}$, but the inching climber would reach the top in $4.6 \mathrm{~h}$. However, it is unlikely that either style of climbing is used continuously in the wild. Awaous guamensis and L. concolor in particular seem to be unable to sustain continuous cycles of rapid powerburst climbing over extended periods of time. Yet, the use of intermittent locomotion (bursts interspersed with pauses) can allow animals to travel a greater total distance before fatigue than would have been possible using sustained locomotion, particularly if pauses in locomotion can bring the average velocity of animals below the speed at which their rate of oxygen consumption is highest (Full \& Weinstein, 1992; Weinstein \& Full, $1992,1998,1999)$. It seems probable that pauses between bouts of powerburst climbing provide A. guamensis and L. concolor with periods of rest that improve their ability to traverse vertical distances tens of thousands of times the length of their bodies. Depending on the duration of locomotor bouts, pauses of only twice the duration of activity bouts can nearly double the distances that animals can travel before fatiguing (Weinstein \& Full, 1999). The duration of pauses that powerburst climbers use is a critical factor in determining the total amount of time that they require to scale waterfalls, but it remains to be measured in the field. Nevertheless, even with pauses that last twice as long as locomotor bouts, the time required for powerburst climbers to scale waterfalls would only triple. Thus, powerburst climbers would still be expected to scale 
waterfalls considerably faster than inching climbers in the wild.

The enormous speeds achieved during powerburst climbing (>12 $\mathrm{BL} \mathrm{s}^{-1}$; Table 2) substantially exceed the minimum speed at which white muscle fibres typically are recruited $\left(2-5 \mathrm{BL} \mathrm{s}^{-1}\right)$, indicating that powerburst climbing probably depends on the activation of white muscles (Jayne \& Lauder, 1994). In contrast, the climbing velocities used during inching by $S$. stimpsoni $\left(0.21 \mathrm{BL} \mathrm{s}^{-1}\right.$ : Table 2) are within the range used by fishes that propel themselves only using longitudinal red muscle fibres ( $<0.5-2.0 \mathrm{BL} \mathrm{s}^{-1}$; Johnston et al., 1977; Bone, Kiceniuk \& Jones, 1978; Videler, 1981; Jayne \& Lauder, 1993, 1994; Gillis, 1998b). White muscle is typically subject to rapid fatigue (Driedzic \& Hochachka, 1978; Videler, 1981; Weber \& Haman, 1996; Sänger \& Stoiber, 2001) which might contribute to the brief durations of powerburst climbing bouts. In contrast, if inching is powered primarily by red muscle, the potential for exhaustion could be greatly reduced in $S$. stimpsoni because red muscle depends upon aerobic metabolism that is suited to endurance behaviours (Driedzic \& Hochachka, 1978; Videler, 1981; Blake, 1983; Sänger \& Stoiber, 2001).

It is noteworthy that juvenile $S$. stimpsoni appear to use the fins and body axis effectively during moderate swimming (pers. obs.). This suggests that $S$. stimpsoni still may be neuromuscularly capable of using powerburst mechanisms, but that they do not implement powerburst behaviours owing to physiological or energetic constraints. Inching up surfaces is almost certainly less energetically costly per cycle than powerburst climbing. Moreover, S. stimpsoni seem to limit locomotor costs further because they exit water and inch up surfaces largely outside the direct flow of current both in the laboratory (Table 2) and in the wild (M. Fitzsimons, pers. comm.). In contrast, powerburst climbers probably incur added energetic costs as they tend to exit pools within current flow and, therefore, must fight downward current in their efforts to ascend vertical surfaces.

\section{Is waterfall climbing aquatic, terrestrial, or both?}

Waterfalls incorporate both aquatic and terrestrial habitats, with water that is often fairly shallow flowing over a rock substrate. Which of these regimes is of primary importance to the locomotor mechanics of climbing fishes? For S. stimpsoni inching up vertical surfaces, the influence of the terrestrial regime clearly seems to predominate. Sicyopterus stimpsoni attach at least one sucking disc to maintain contact with the solid substrate at all times during climbing cycles, and show no evidence of body or fin movements consistent with undulatory or labriform modes of aquatic propulsion. These climbing kinematics most closely resemble the techniques observed in some catfishes as they alternately attach oral suckers and bony pelvic plates to the vertical substrates that they ascend (Evermann \& Kendall, 1905; Johnson, 1912). Moreover, S. stimpsoni frequently climb surfaces outside of direct current flow (Table 1). Wetting of the climbing substrate is probably critical to the mechanics of suction (e.g. Yazdani, 1983), but climbing in S. stimpsoni seems to be simply a form of terrestrial locomotion on a wet vertical substrate.

Evaluating the predominant locomotor regime for powerburst climbers is less straightforward. The initiation of a powerburst seems to depend on terrestrial mechanisms: powerburst gobies begin cycles with the pelvic disc contacting the substrate, and begin propulsion by pushing against the substrate with their pectoral fins to generate a ground reaction force. The kinematics of sustained powerburst climbing in gobies also display several similarities to the kinematics of terrestrial locomotion in freshwater American eels Anguilla rostrata. In eels, undulations during aquatic locomotion are limited to caudal body segments, but locomotion over horizontal terrestrial substrates is accomplished using high-amplitude undulations that are passed along the entire length of the body (Gillis, 1998a). During powerburst climbing, A. guamensis and L. concolor also display high-amplitude undulations along the entire length of the body, despite lacking the axial elongation typical of eels. However, in undulatory locomotion on terrestrial substrates, propulsive forces are believed to be produced at positions along the body where low undulatory amplitudes and low minimum resultant velocities coincide (Gillis, 1998a). In American eels, for instance, points along the body that experience the lowest undulatory amplitudes also experience the lowest resultant velocities $\left(<0.25 \mathrm{BL} \mathrm{s}^{-1}\right.$; Gillis, 1998a). Although the body region in which amplitude and resultant velocity are lowest also coincide in powerburst climbing gobies (at 20-30\% BL from the head: Fig. 6), the minimum resultant velocities of all points along the body are high in A. guamensis and L. concolor, generally exceeding $6 \mathrm{BL} \mathrm{s}^{-1}$. These high resultant velocities suggest that large levels of thrust may not be generated at these low-amplitude locations. Furthermore, in contrast to S. stimpsoni, A. guamensis and L. concolor rarely initiate climbing bouts by exiting the water completely outside of flow (Table 1). It therefore seems possible that, in order to scale waterfalls, powerburst climbers might supplement the mechanisms for generation of terrestrial thrust with aquatic mechanisms. Evaluation of those mechanisms is complicated by the thinness of the water layer through which the fishes climbed, an aspect of our experiments designed to replicate field observations (Schoenfuss, 1997). None the less, it is possible that powerburst climbing represents a novel mode of locomotion that hybridizes components of terrestrial and aquatic propulsive mechanics.

\section{Correspondences between ontogeny, ecology, and locomotor physiology in Hawaiian gobies}

The genus Sicyopterus is nested phylogenetically between Awaous and Lentipes (Parenti \& Thomas, 1998), suggesting that $S$. stimpsoni may have evolved from a powerburst climbing ancestor and that its distinctive ontogeny and locomotor behaviours are evolutionary novelties, 
rather than ancestral retentions. The performance characteristics of inching climbing in S. stimpsoni suggest compelling correlations between the climbing style, ontogenetic history, and ecological strategies of this species. Oceanic larval development in the powerburst climbers A. guamensis and L. concolor lasts 3 months, similar to the duration observed in the non-climbing gobioid fish of the Hawaiian freshwater ecosystem (Stenogobius hawaiiensis) (Ego, 1956). In contrast, the ontogenetic history of $S$. stimpsoni is unique among Hawaiian gobies. In S. stimpsoni, oceanic larval development lasts 6 months, twice as long as in other Hawaiian gobies, and includes an extensive cranial metamorphosis during which larvae do not feed (Schoenfuss et al., 1997). As a result, by the time juvenile $S$. stimpsoni begin to climb up waterfalls upon the completion of metamorphosis, they have experienced a $15 \%$ loss of body weight (Schoenfuss, 1997). Protein is a major source of energy for most fishes, and during starvation many fish species have been found to break down muscle protein (Moon, 1983). However, different muscle fibre types of fishes show distinct responses to starvation: whereas the contractile proteins of white muscle are degraded, the structural integrity of red muscle typically remains intact (Johnston \& Goldspink, 1973; Patterson, Johnston \& Goldspink, 1974; Johnston, 1981; Beardall \& Johnston, 1983; Loughna \& Goldspink, 1984; Kiran \& Talesara, 1985; Black \& Love, 1986; Maddock \& Burton, 1994). The mobilization of muscle protein has been indicated in some fishes after periods of starvation as brief as $36 \mathrm{~h}$ (Kutty, 1972), shorter than observed in S. stimpsoni. Thus, during metamorphosis $S$. stimpsoni may be experiencing a level of nutritional stress comparable to that of other starved species of fish and, consequently, also might be expected to degrade white muscle. In the light of the tendency among fishes to deplete or impair white muscle during starvation (Kiessling, Johanssen \& Kiessling, 1990), it seems probable that the evolution of the unique metamorphic strategy of $S$. stimpsoni would have been closely correlated with the evolution of a style of climbing that could be powered by red muscle. The slow speed of inching, and the specific body movements it uses, are both consistent with red muscle as its source of power.

The enormous differences in kinematics and performance that we have quantified between the two climbing styles used by Hawaiian gobies indicate that considerable diversity in locomotor mechanisms is possible even under the potentially constraining demands of an environment as extreme as waterfalls. However, performance and energetic costs of climbing for these species remain to be determined for travel up entire waterfalls in the wild. In addition, the effects of variation in a variety of environmental parameters that might affect climbing performance, such as water flow rate or substrate roughness, have yet to be evaluated. The performance effects of variation in anatomical features also have yet to be examined, and the muscles powering each climbing style remain to be determined. Our comparative analyses of the kinematics and performance of these species thus lay the foundation for several mechanistic, ecological, and evolutionary investigations that will provide directions for a wide range of future integrative research on this system.

\section{Acknowledgements}

We thank D. G. Kuamo'o for collecting the goby specimens used in this study and for the design and construction of the artificial waterfall; $\mathrm{M}$. Westneat for access to video equipment and facilities; J. Walker for access to QuickImage, QuicKurve, and QuickSAND software; and R. Kinzie III and S. Monden for permitting use of the illustrations of goby species shown in Fig. 1. N. Espinoza, M. Fitzsimons, J. Socha, M. Westneat, J. Willey, and two anonymous referees provided helpful reviews of manuscript drafts. We also benefitted from discussions with R. Nishimoto, M. LaBarbera, J. Walker, R. Thomas, and J. Janovetz. P. Willink and T. Hsieh alerted us to relevant literature, and the Cooper Library of Clemson University provided valuable assistance in locating literature. We thank S. Reilly and A. Biknevicius (Ohio University), the organizers of the first Midwest Regional Meeting of the Division of Vertebrate Morphology, Society for Integrative and Comparative Biology for providing a forum for the discussions that stimulated our collaboration on this study. Funding for goby collection and study was provided by Hawai'i Division of Aquatic Resources, Sport Fish Restoration Project F-14-R-18 to M. Fitzsimons. Funding for video equipment was provided by Office of Naval Research grant N000149910184 to M. Westneat and J. Walker. Initial work on this study by RWB was supported by National Institutes of Health NRSA fellowships (1F32NS1081301 and 5F32NS10813-02). Final analyses and manuscript preparation were supported by St Cloud State University (HLS) and Clemson University (RWB).

\section{REFERENCES}

Batty, R. S. (1981). Locomotion of plaice larvae. Symp. zool. Soc. Lond. No. 48: 53-69.

Beardall, C. H. \& Johnston, I. A. (1983). Muscle atrophy during starvation in a marine teleost. Eur. J. Cell Biol. 29: 209-217.

Blake, R. W. (1983). Fish locomotion. Cambridge: Cambridge University Press.

Black, D. \& Love, R. M. (1986). The sequential mobilization and restoration of energy reserves in tissues of Atlantic cod during starvation and refeeding. J. comp. Physiol. B biochem. syst. environ. Physiol. 156: 469-479.

Bone, Q., Kiceniuk, J. \& Jones, D. R. (1978). On the role of the different fibre types in fish myotomes at intermediate swimming speeds. Fish. Bull. Fish Wildl. Serv. U.S.A. 76: 691-699.

Buckup, P. A., Zamprogno, C., Vieira, F. \& Teixeira, R. L. (2000). Waterfall climbing in Characidium (Crenuchidae: Characidiinae) from eastern Brazil. Ichthyol. Explor. Freshwaters 11: $273-278$.

Driedzic, W. R. \& Hochachka, P. W. (1978). Metabolism in fish during exercise. In Fish physiology VII: 503-543. Hoar, W. S. \& Randall, D. J. (Eds). New York: Academic Press.

Eigenmann, C. H. (1905). The freshwater fishes of British Guiana including a study of the ecological grouping of species and the relation of the fauna of the plateau to that of the lowlands. Mem. Carnegie Mus. 5: 1-578. 
Eigenmann, C. H. (1918). The Pygidiidae, a family of South American catfishes. Mem. Carnegie Mus. 7: 259-398.

Ego, K. (1956). Life history of fresh water gobies. Project No. 4-4-R. Honolulu, HI: Fresh Water Game Fish Management Research.

Evermann, B. W. \& Kendall, W. C. (1905). An interesting species of fish from the high Andes of central Ecuador. Proc. Biol. Soc. Wash. 18: 91-106.

Fitzsimons, J. M., Nishimoto, R. T. \& Yuen, A. R. (1993). Courtship and territorial behaviour in the native Hawaiian stream goby, Sicyopterus stimpsoni. Ichthyol. Explor. Freshwaters 4: 1-10.

Fitzsimons, J. M. \& Nishimoto, R. T. (1995). Use of fish behaviour in assessing the effects of Hurricane Iniki on the Hawaiian island of Kaua'i. Environ. Biol. Fish. 43: 39-50.

Fitzsimons, J. M. \& Nishimoto, R. T. (1996). Recovery of three Kaua'i streams from hurricane Iniki and implications for the restoration and regeneration of freshwater ecosystems in Hawai'i. In Will stream restoration benefit freshwater, estuarine, and marine fisheries?: 69-75. Devick, W. S. (Ed.). Honolulu: State of Hawai'i.

Ford, J. I. \& Kinzie, R. A. (1982). Life crawls upstream. Nat. Hist. 91: 61-67.

Fukui, S. (1979). On the rock-climbing behaviour of the goby, Sicyopterus japonicus. Jpn. J. Ichthyol. 26: 84-88.

Full, R. J. \& Weinstein, R. B. (1992). Integrating the physiology, mechanics, and behaviour of rapid running ghost crabs: slow and steady doesn't always win the race. Am. Zool. 32: 382-395.

Gillis, G. B. (1996). Undulatory locomotion in elongate aquatic vertebrates: aguilliform swimming since Sir James Gray. Am. Zool. 36: 656-665.

Gillis, G. B. (1998a). Environmental effects on undulatory locomotion in the American eel Anguilla rostrata: kinematics in water and land. J. exp. Biol. 201: 949-961.

Gillis, G. B. (1998b). Neuromuscular control of anguilliform locomotion: patterns of red and white muscle activity during swimming in the American eel, Anguilla rostrata. J. exp. Biol. 201: $3245-3256$

Harris, V. A. (1960). On the locomotion of the mud-skipper Periophthalmus koelreuteri (Pallas): (Gobiidae). Proc. zool. Soc. Lond. 134: 107-135.

Hunter, J. R. (1972). Swimming and feeding behaviour of larval anchovies Engraulis mordax. Fish. Bull. 70: 821-838.

Hunter, J. R. \& Kimbrell, C. A. (1979). Early life history of Pacific mackerel, Scomber japonicus. Fish. Bull. 78: 89-101.

Jayne, B. C. \& Lauder, G. V. (1993). Red and white muscle activity and kinematics of the escape response of the bluegill sunfish during swimming. J. comp. Physiol. A sens. neural. behav. Physiol. 173: 495-508.

Jayne, B. C. \& Lauder, G. V. (1994). How fish use slow and fast muscle fibers: implications for models of vertebrate muscle recruitment. J. comp. Physiol. A sens. neural. behav. Physiol. 175: $123-131$.

Jayne, B. C. \& Lauder, G. V. (1995). Speed effects on midline kinematics during steady undulatory swimming of largemouth bass, Micropterus salmoides. J. exp. Biol. 198: 585-602.

Johnson, R. D. O. (1912). Notes on the habits of a climbing catfish (Arges marmoratus) from the Republic of Columbia. Ann. N. Y. Acad. Sci. 22: 327-333.

Johnston, I. A. (1981). Quantitative analysis of muscle breakdown during starvation in the marine flatfish Pleuronectes platessa. Cell Tissue Res. 214: 369-386.

Johnston, I. A., Davison, W. \& Goldspink, G. (1977). Energy metabolism of carp swimming muscles. J. Comp. Physiol. B 114: $203-216$.

Johnston, I. A. \& Goldspink, G. (1973). Some effects of prolonged starvation on the metabolism of the red and white myotomal muscles of the plaice Pleuronectes platessa. Mar. Biol. 19: 348353.

Kiessling, A., Johansson, L. \& Kiessling, K.-H. (1990). Effects of starvation on rainbow trout muscle: I. Histochemistry, metabolism and composition of white and red muscle in mature and immature fish. Acta Agric. Scand. 40: 309-324.

Kinzie, R. A. III. (1990). Species profiles: life history and environmental requirements of coastal vertebrates and invertebrates, Pacific Ocean Region; Report 3, amphidromous macrofauna of island streams. Technical Report EL-89-10. Vicksburg, MS: U.S. Army Engineers Waterways Experiment Station.

Kiran, S. \& Talesara, C. L. (1985). Prolonged starvation effects on myotomal muscles of two fresh water teleost fishes - murrel (Channa punctata) and catfish (Clarias batrachus). Indian J. exp. Biol. 23: 17-22.

Kottelat, M. (1988). Two species of cavefishes from northern Thailand in the genera Nemacheilus and Homaloptera (Osteichthyes: Homalopteridae). Rec. Aust. Mus. 40: 225-231.

Kutty, M. N. (1972). Respiratory quotient and ammonia excretion in Tilapia mossambica. Mar. Biol. 16: 126-133.

Long, J. H., Jr, McHenry, M. J. \& Boetticher, N. C. (1994). Undulatory swimming: how traveling waves are produced and modulated in sunfish (Lepomis gibbosus). J. exp. Biol. 192: 129145 .

Loughna, P. T. \& Goldspink, G. (1984). The effects of starvation upon protein turnover in red and white myotomal muscle of rainbow trout, Salmo gairdneri Richardson. J. Fish Biol. 25 : 223-230.

Maddock, D. M. \& Burton, M. P. M. (1994). Some effects of starvation on the lipid and skeletal muscle layers of the winter flounder, Pleuronectes americanus. Can. J. Zool. 72: 1672-1679.

Moon, T. W. (1983). Metabolic reserves and enzyme activities with food deprivation in immature American eels, Anguilla rostrata (LeSeur). Can. J. Zool. 61: 802-811.

Moriarty, C. (1978). Eels. New York: Universe Books.

Nishimoto, R. T. \& Fitzsimons, J. M. (1999). Behavioral determinants of the instream distribution of native Hawaiian stream fishes. In Proceedings of the Fifth Indo-Pacific Fish Conference, Nouméa (1997): 813-818. Séret, B. \& Sire, J.-Y. (Eds). Paris: Societe Francaise d'Ichtyologie.

Nishimoto, R. T. \& Kuamo'o, D. G. K. (1992). Waterfall climbing behaviour in the postlarvae of native Hawaiian stream gobies. Technical paper. Hawai'i: Division of Aquatic Resources.

Nishimoto, R. T. \& Kuamo'o, D. G. K. (1997). Recruitment of goby postlarvae into Hakalau stream, Hawai'i island. Micronesica 30: 41-49.

Parenti, L. R. \& Thomas, K. R. (1998). Pharyngeal jaw morphology and homology in sicydiine gobies (Teleostei: Gobiidae) and allies. J. Morphol. 237: 257-274.

Patterson, S., Johnston, I. A. \& Goldspink, G. (1974). The effect of starvation on the chemical composition of red and white muscles in the plaice (Pleuronectes platessa). Experientia 30: 892894.

Reidy, S. P., Kerr, S. R. \& Nelson, J. A. (2000). Aerobic and anaerobic swimming performance of individual Atlantic cod. J. exp. Biol. 203: 347-357.

Rohlf, F. J. \& Sokal, R. R. (1995). Statistical tables. 3rd edn. New York: W. H. Freeman.

Sänger, A. M. \& Stoiber, W. (2001). Muscle fibre diversity and plasticity. In Fish physiology 18: 187-250. Johnston, I. A. (Ed.). San Diego: Academic Press.

Schoenfuss, H. L. (1997). Metamorphosis of the Hawaiian stream goby Sicyopterus stimpsoni: a structural, functional, and behavioral analysis. $\mathrm{PhD}$ thesis, Louisiana State University.

Schoenfuss, H. L., Blanchard, T. A. \& Kuamo'o, D. G. G. (1997). Metamorphosis in the cranium of postlarval Sicyopterus stimpsoni, an endemic Hawaiian stream goby. Micronesica 30: 93-104.

Sokal, R. R. \& Rohlf, F. J. (1995). Biometry. 3rd edn. New York: W. H. Freeman.

Summers, A. P. \& O'Reilly, J. C. (1997). A comparative study of locomotion in the caecilians Dermophis mexicanus and 
Typhlonectes natans (Amphibia: Gymnophiona). Zool. J. Linn. Soc. 121: 65-76.

Tate, D. C. (1997). The role of behavioral interactions of immature Hawaiian stream fishes (Pisces: Gobiodei) in population dispersal and distribution. Micronesica 30: 51-70.

Todd, E. S. (1976). Terrestrial grazing by the eastern tropical Pacific goby Gobionellus sagittula. Copeia 1976: 374-377.

Videler, J. J. (1981). Swimming movements, body structure and propulsion in cod Gadus morhua. Symp. zool. Soc. Lond. No. 48 : $1-27$.

Voegtlè, B., Larinier, M. \& Bosc, P. (2002). Ètude sur les capcitès de franchissement des cabot bouche-rondes (Sicyopterus lagocephalus, Pallas, 1770) en vue de la conception de dispositifs adaptés aux prises d'eau du transfert Salazie (Île de la Reunion). Bull. fr. Pêche Piscic. 364: 109-120.

Wainwright, S. A., Vosburgh, F. \& Hebrank, J. H. (1978). Shark skin: function in locomotion. Science 202: 747-749.

Walker, J. A. (1998). Estimating velocities and accelerations of animal locomotion: a simulation experiment comparing numerically different algorithms. J. exp. Biol. 201: 981-995.
Walker, J. A. (2000). Does a rigid body limit maneuverability? J. exp. Biol. 203: 3391-3396.

Webb, P. W. (1984). Body form, locomotion and foraging in aquatic vertebrates. Am. Zool. 24: 107-120.

Weber, J.-M. \& Haman, F. (1996). Pathways for metabolic fuels and oxygen in high performance fish. Comp. Biochem. Physiol. A comp. Physiol. 113: 33-38.

Weinstein, R. B. \& Full, R. J. (1992). Intermittent exercise alters endurance in an eight-legged ectotherm. Am. J. Physiol. 262: R852-R859.

Weinstein, R. B. \& Full, R. J. (1998). Performance limits of low-temperature, continuous locomotion are exceeded when locomotion is intermittent in the ghost crab. Physiol. Zool. 71: 274-284.

Weinstein, R. B. \& Full, R. J. (1999). Intermittent locomotion increases endurance in a gecko. Physiol. Biochem. Zool. 72: 732739.

Yazdani, G. M. (1983). Mechanism of vacuum formation in the thoracic disc of hill-stream catfish, Pseudecheneis salcatus (McClell.). Bull. zool. Surv. India 5: 71-75. 